\title{
Residual limb skin temperature and thermal comfort in people with amputation during activity in a cold environment
}

\author{
Ava D. Segal, MS; ${ }^{1}$ Glenn K. Klute, PhD $^{1-2^{*}}$ \\ ${ }^{1}$ Center for Limb Loss Prevention and Prosthetic Engineering, Rehabilitation Research and Development, Department \\ of Veterans Affairs, Puget Sound Health Care System, Seattle, WA; ${ }^{2}$ Department of Mechanical Engineering, Univer- \\ sity of Washington, Seattle, WA
}

\begin{abstract}
Thermal comfort remains a common problem for people with lower-limb amputation. Both donning a prosthesis and engaging in activity at room temperature can increase residual limb skin temperature; however, the effects of activity on skin temperature and comfort in more extreme environments remain unknown. We examined residual limb skin temperatures and perceived thermal comfort (PTC; 11-point Likert scale) of participants with unilateral transtibial amputation $(n=$ 8) who were snowshoeing in a cold environment. Residual limb skin temperature increased by $3.9^{\circ} \mathrm{C}\left(3.0^{\circ} \mathrm{C}\right.$ to $\left.4.7^{\circ} \mathrm{C}\right)$ (mean difference [95\% confidence interval], $p<0.001$ ) after two 30 min exercise sessions separated by a 5 min rest session. Minimal cooling $\left(-0.2^{\circ} \mathrm{C}\left[-1.1^{\circ} \mathrm{C}\right.\right.$ to $\left.\left.0.6^{\circ} \mathrm{C}\right]\right)$ occurred during the rest period. Similar changes in PTC were found for the residual limb, intact limb, and whole body, with a mean scale increase of 1.6 (1.1 to 2.1) and 1.3 (0.8 to 1.8) for the first and second exercise sessions, respectively $(p<0.001)$. Activity in a cold environment caused similar increases in residual limb skin temperature as those found in studies conducted at room temperature. Participants with amputation perceived warming as their skin temperature increased during exercise followed by the perception of cooling during rest, despite minimal associated decreases in skin temperature.
\end{abstract}

Key words: amputation, cold environment, exercise, lowerlimb, prosthesis, skin temperature, snowshoe, thermal comfort, thermistor, transtibial.

\section{INTRODUCTION}

The residual limb skin temperatures of people with lower-limb amputation increase after merely donning a prosthesis and continue to rise at a rate contingent on activity level [1-2]. These elevated skin temperatures negatively affect quality of life for individuals with amputation, with more than 53 percent reporting discomfort from heat and/or perspiration inside their prosthetic socket in 38 reviewed studies [3]. The tight-fitting liner at the skinsocket interface required to maintain adherence and transfer forces to the residual limb lacks the ability to regulate temperature because of limited air convection, evaporative mechanisms [4], and thermal conductivity [5], trapping heat and contributing to thermal discomfort and skin breakdown. In a study of 90 subjects with transfemoral amputation, 72 percent reported that heat and sweat at least moderately affected their quality of life, with 62 percent reporting sores and skin irritation from their socket [6].

\footnotetext{
Abbreviations: Exercise1 = first 30 min exercise period, Exercise2 = second 30 min exercise period, $\mathrm{MG}=$ medial gastrocnemius, PTC = perceived thermal comfort, Rest1 = initial 5 min standing rest period, Rest $2=$ second 5 min standing rest period, Rest $3=$ third 5 min standing rest period, $\mathrm{SD}=$ standard deviation, $\mathrm{TA}=$ tibialis anterior.

*Address all correspondence to Glenn K. Klute, PhD; 1660 S. Columbian Way, Seattle, WA 98108; 206-277-6724; fax: 206-764-2808. Email: gklute@u.washington.edu http://dx.doi.org/10.1682/JRRD.2015.03.0053
} 
A comprehensive understanding of the residual limb's skin temperature and the corresponding thermal comfort of the individual with amputation in more extreme environmental conditions would better inform design criteria for more comfortable prostheses. Without a prosthesis, the residual limb of a person with amputation is on average $1^{\circ} \mathrm{C}$ cooler than the contralateral limb [7], suggesting that maintaining lower skin temperatures through improved socket technology may be warranted. A prior study examined residual limb skin temperatures $(n=9)$ during a $30 \mathrm{~min}$ walking session in a moderate ambient room temperature $\left(\sim 20^{\circ} \mathrm{C}\right)$ and reported a $3^{\circ} \mathrm{C}$ increase in skin temperature followed by little cooling $\left(<1^{\circ} \mathrm{C}\right)$ after prolonged rest (60 min) [2]. Mathur et al. also reported a residual limb skin temperature increase $\left(2^{\circ} \mathrm{C}\right)$ during a 10 min walk at $0.6 \mathrm{~m} / \mathrm{s}$ in a $20^{\circ} \mathrm{C}$ chamber $(n=1)$, but temperatures remained constant when the chamber temperature was $10^{\circ} \mathrm{C}$ [8]. However, the effect of cold ambient temperatures $\left(0^{\circ} \mathrm{C}\right)$, as are frequently experienced during winter months, on residual limb skin temperatures remains unknown. This knowledge would demonstrate whether the residual limb remains insulated within the prosthetic socket during activity despite exposure to a cold environment or, alternatively, whether a special thermal system is required. Therefore, the goal of this study was to record residual limb skin temperatures and perceived thermal comfort (PTC) in a cold environment during moderate activity under realistic field conditions.

\section{METHODS}

\section{Participants}

Active males with unilateral transtibial amputation who already participated in snow sports (e.g., skiing, snowboarding, or snowshoeing) were recruited to participate in this institutional review board-approved study. Participants were between 18 and 70 yr of age, wore their prosthesis at least $8 \mathrm{~h}$ per day, were at least $2 \mathrm{yr}$ postamputation, were able to ambulate without upper-limb aids, and had no history of falls within the previous 6 mo. Lastly, they were able to detect the touch of a SemmesWeinstein 5.07 monofilament (10 g force; CHS Services, Inc; East Setauket, New York), used to make skin contact, bend, and depart the skin at each temperature sensor site.

\section{Instrumentation}

In-socket skin temperatures were measured at four locations on the residual limb with thermistor sensors (MA100DD 103A, Thermometrics, Inc; Edison, New Jersey; diameter kapton sleeve: $1.3 \mathrm{~mm}$, length: $9.5 \mathrm{~mm}$ ). Prior to application, these sensors were validated in a water bath using a National Institute of Standards and Technology-calibrated instrument $\left(<0.3^{\circ} \mathrm{C}\right.$ error [9]). To aid sensor placement on the residual limb, lines were drawn that bisected it into proximal and distal locations. The thermistors were then placed in the middle of the proximal and distal locations of the tibialis anterior (TA) and the medial gastrocnemius (MG) to avoid bony landmarks that might increase the chance of skin breakdown and wire failure (Figure 1). After thermistor wires (32-gauge bifilar heavy isomid insulation, length: $610 \mathrm{~mm}$ ) were secured with thin fabric tape, the participant donned his prosthesis. Tape was not placed directly on the sensor because it can act as an insulator and affect the gathered data. We confirmed that sensor displacement was minimized by photographing the instrumented limb before donning and after doffing the prosthesis. The wires exited at the proximal end of the liner and were routed beneath clothing to a data logger (Smart Reader Plus 8, ACR Systems Inc; Surry, British Columbia, Canada; range: $-40^{\circ} \mathrm{C}$ to $70^{\circ} \mathrm{C}$, tolerance: $\pm 0.15^{\circ} \mathrm{C}$, resolution: $0.07^{\circ} \mathrm{C}$ ) worn in a small pack around the waist. Skin temperature data were collected at $0.125 \mathrm{~Hz}$.

PTC was measured by asking participants to rate the thermal comfort of their residual limb, intact limb, and whole body at the beginning and end of each exercise bout using an 11-point Likert psychometric scale ( 0 being cold, 5 being most comfortable, and 10 being hot). The
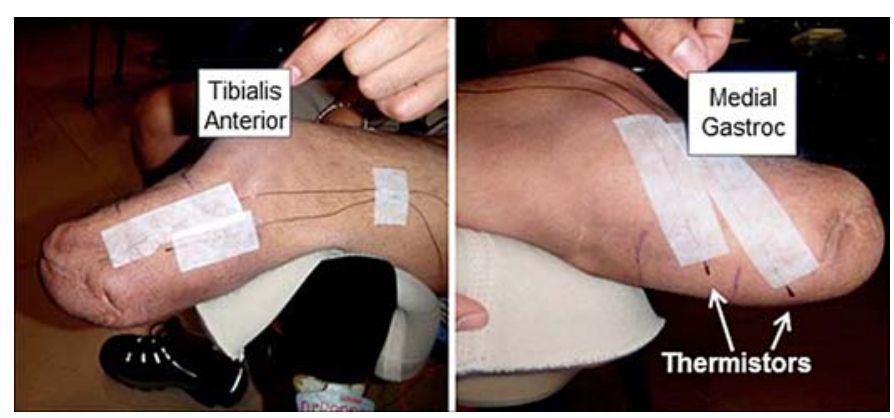

Figure 1.

Representative photographs of thermistor placements on the lateral tibialis anterior and medial gastrocnemius (Gastroc) of the residual limb. The lines on the anterior and posterior sides of the residual limb were drawn to guide thermistor placement. 
scale was adapted from the psychophysical 7-point thermal comfort scale [10-11]. We chose an 11-point scale because it was suggested to reduce skewness, minimize kurtosis, and be closest to normal [12].

Internal body temperature was measured with an ingestible sensor that the subjects swallowed at least $2 \mathrm{~h}$ prior to data collection (HT 150001, CorTemp® Recorder, HQ Inc; Palmetto, Florida). While inside the gastrointestinal tract, the sensor's internal crystal sensor vibrates at a frequency relative to the temperature of the body, producing a measurable magnetic flux. The sensor transmits the core body temperature signal harmlessly through the body to a data recorder worn on the waist pack. The CorTemp ${ }^{\circledR}$ sensor is a Food and Drug Administration-registered, single use, class 2 device, which is accurate to $\pm 0.1^{\circ} \mathrm{C}$, with a range from $30^{\circ} \mathrm{C}$ to $45^{\circ} \mathrm{C}$ and calibrated to $\pm 0.05^{\circ} \mathrm{C}$.

Heart rate was measured using a Polar heart rate monitor (RS400, Polar; Kempele, Finland) to estimate work load. This device did not have data logging capacity; therefore, we manually recorded heart rate every 2 min throughout the exercise protocol. Each participant also wore a StepWatch 3 Activity Monitor (Orthocare Innovations; Mountlake Terrace, Washington) on the lateral side of the prosthetic pylon to measure step count and cadence during the testing session. This pager-sized device $(70 \times 50 \times 20 \mathrm{~mm}$; $38 \mathrm{~g})$ was used to record the number of strides taken during $1 \mathrm{~min}$ intervals and has been shown to be accurate [13] with high test-retest reliability [14-15]. The step data were also used to identify the specific times during the testing session when continuous walking occurred.

\section{Protocol}

Once participants were fully instrumented and dressed in their typical snowshoe gear (thermal under layer and waterproof outer layers), we traveled $45 \mathrm{~min}$ by passenger van at a comfortable temperature chosen by the passengers to a mountain pass (Snoqualmie Pass, Washington; elevation: $921 \mathrm{~m}$ ) with a snowshoe course set up in a large open field (Figure 2). Participants completed laps around this course to remain within close proximity of the van at all times as an added safety precaution. The protocol began with an initial 5 min standing rest period (Rest1). Just before starting to walk, the participants reported the PTC of their residual limb, intact limb, and whole body. Then subjects walked continuously for $30 \mathrm{~min}$ at a self-selected speed around the snowshoe course (first 30 min exercise period [Exercise1]), reading off heart rate measurements every 2 min, which were recorded by a researcher walking behind the participants. After completing Exercise1, subjects rated their PTC and then completed a second $5 \mathrm{~min}$ standing rest period (Rest2). Just before beginning the second walking bout, subjects again rated their PTC. After a second 30 min continuous walking session at self-selected speed (second 30 min exercise period [Exercise2]), subjects rated their PTC. The final $5 \mathrm{~min}$ standing rest session (Rest3) was completed, followed by a PTC rating. Residual limb skin temperature, internal body temperature, and step count were measured continuously throughout the testing



Figure 2.

Photographs depict the environment of the snowshoe walking course and examples of the exterior clothing worn during three different data collections. 
session. Once the protocol was complete, we traveled back to the laboratory, where the instrumentation was removed. We noted if any thermistors or their wires broke during the test or appeared to have moved from their initial placement.

\section{Data Analysis}

Thermistor and core temperature data from the last minute of each bout were averaged across participants. Mean heart rate was calculated at the end of each rest session and the average at steady state during the exercise session (not including the first and last 2 min readings) was also calculated across participants. Step count data were multiplied by two to determine the total steps taken with both the prosthetic and intact limbs.

Linear mixed-effects regression was used to estimate mean differences in residual limb skin temperature by bout, adjusting for thermistor location. This model accounts for nonindependence of data due to repeated measures within subject by estimating separate errors for between and within subjects. Temperature was the dependent variable, bout and location were independent fixed effects, and subject was modeled as a random effect. Similarly, linear mixed-effects regression was used to estimate mean differences in PTC by bout and region of the body, with PTC as the dependent variable, bout and region as independent fixed effects, and subject as a random effect.

If the omnibus test for the association between dependent and independent variables was significant, pairwise comparisons were carried out using simultane- ous inference [16]. Data analysis was completed using $\mathrm{R}$ 3.1.0 [17]; the lme4 package was used to carry out the linear mixed-effects regression [18], and the multcomp package was used to carry out the pairwise comparisons [19].

\section{RESULTS}

Eight active males with unilateral transtibial amputation met inclusion criteria and gave informed consent to participate. The participants' mean \pm standard deviation (SD) age was $53 \pm 12 \mathrm{yr}$, height was $1.8 \pm 0.1 \mathrm{~m}$, weight was $82 \pm 7.4 \mathrm{~kg}$, and time since amputation was $22 \pm 14 \mathrm{yr}$. Participant demographics and archived ambient temperatures from Snoqualmie Pass are shown in Table 1. Prosthetic prescriptions and clothing worn during the experiment are shown in Table 2.

An overall significant association existed between residual limb skin temperature and bout $(p<0.001)$. Mean \pm SD residual limb skin temperature (Figure 3, Table 3) increased from $30.6^{\circ} \mathrm{C} \pm 2.6^{\circ} \mathrm{C}$ at Rest 1 to $34.5^{\circ} \mathrm{C} \pm 1.7^{\circ} \mathrm{C}$ at the end of Exercise 2 across participants and thermistor location (difference [95\% confidence interval]: $3.9^{\circ} \mathrm{C}$ [3. $0^{\circ} \mathrm{C}$ to $\left.\left.4.7^{\circ} \mathrm{C}\right], p<0.001\right)$. At the end of Exercise1, residual limb skin temperature increased $\left(2.7^{\circ} \mathrm{C}\left[1.8^{\circ} \mathrm{C}\right.\right.$ to $\left.3.5^{\circ} \mathrm{C}\right]$ ) compared with Rest $1(p<0.001)$, followed by an insignificant decrease $\left(-0.3^{\circ} \mathrm{C}\left[-1.1^{\circ} \mathrm{C}\right.\right.$ to $\left.\left.0.6^{\circ} \mathrm{C}\right]\right)$ after

Table 1.

Participant demographics, ambient conditions, and collection information.

\begin{tabular}{|c|c|c|c|c|c|c|c|c|c|}
\hline $\begin{array}{c}\text { Participant } \\
\text { Number }\end{array}$ & $\begin{array}{l}\text { Age } \\
(y r)\end{array}$ & $\begin{array}{c}\text { Time } \\
\text { Postamputation } \\
\text { (yr) }\end{array}$ & $\begin{array}{c}\text { Height } \\
\text { (m) }\end{array}$ & $\begin{array}{c}\text { Body } \\
\text { Mass } \\
(\mathbf{k g})\end{array}$ & Etiology & Total Steps & $\begin{array}{l}\text { Recorded } \\
\text { Thermistors }\end{array}$ & Precipitation & $\begin{array}{c}\text { Archive } \\
\text { Snoqualmie } \\
\text { Pass } \\
\text { Temperatures } \\
\left({ }^{\circ} \mathrm{C}\right)^{*}\end{array}$ \\
\hline 1 & 62 & 39 & 1.92 & 83.6 & Trauma & 6,222 & TA2 & Rain & $3 \pm 2$ \\
\hline 2 & 60 & 34 & 1.78 & 82.3 & Trauma & 6,698 & MG1 & Rain & $3 \pm 2$ \\
\hline 4 & 43 & 17 & 1.80 & 78.6 & Infection & 6,446 & TA2, MG1, MG2 & Rain & $1 \pm 2$ \\
\hline 5 & 31 & 8 & 1.80 & 72.8 & Trauma & 7,050 & $\begin{array}{l}\text { TA1, TA2, MG1, } \\
\text { MG2 }\end{array}$ & Rain & $1 \pm 2$ \\
\hline 6 & 50 & 27 & 1.88 & 84.5 & Trauma & 6,398 & $\begin{array}{l}\text { TA1, TA2, MG1, } \\
\text { MG2 }\end{array}$ & Snow & $-2 \pm 3$ \\
\hline
\end{tabular}

${ }^{*}$ Archived temperatures from www.meteoblue.com.

$\mathrm{TA}=$ tibialis anterior, $\mathrm{MG}=$ medial gastrocnemius . 
Table 2.

Participant prosthetic prescriptions and exterior clothing worn during testing session.

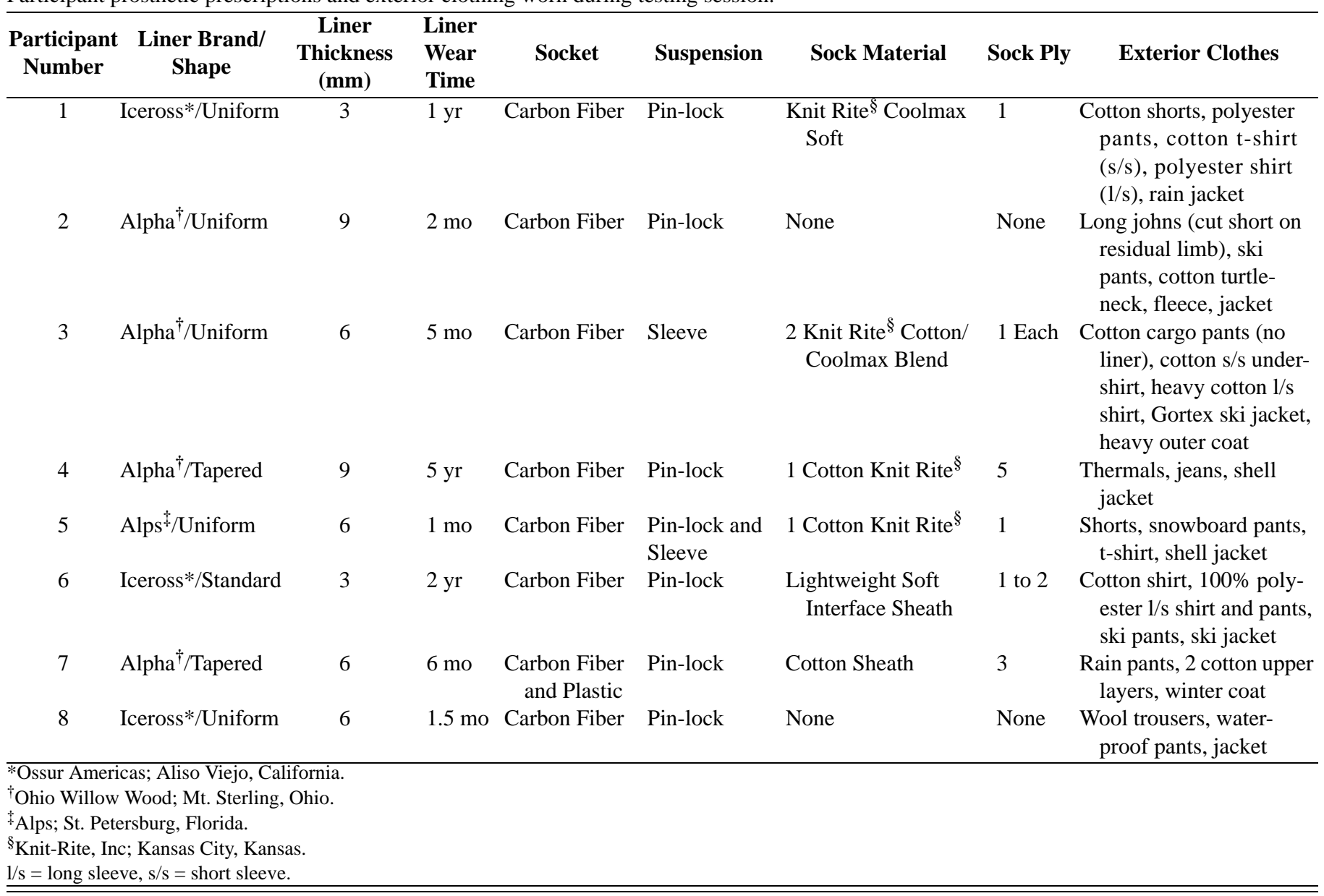

Rest2. After Exercise2, a further increase $\left(1.5^{\circ} \mathrm{C}\left[0.6^{\circ} \mathrm{C}\right.\right.$ to $\left.2.3^{\circ} \mathrm{C}\right]$ ) occurred compared with Rest2 $(p=0.005)$, followed by insignificant cooling at the end of Rest $3\left(-0.4^{\circ} \mathrm{C}\right.$ $\left[-1.2^{\circ} \mathrm{C}\right.$ to $\left.\left.0.5^{\circ} \mathrm{C}\right]\right)$ compared with Exercise2.

An overall significant association existed between PTC and bout $(p<0.001)$; however, the participants perceived similar changes in thermal comfort by region (body, residual limb, and intact limb) during exercise in the cold environment (Figure 4, Table 4). Compared with Rest1, mean PTC across all regions increased for Exercise1 (1.6 [1.1 to 2.1], $p<0.001)$ and Exercise2 (1.3 [0.8 to 1.8], $p<0.001)$. Across bouts, residual limb PTC was 0.7 [0.3 to 1.1$]$ higher than the intact $\operatorname{limb}(p=0.003)$.

Skin temperatures varied across subject and thermistor location, with initial residual limb skin temperature ranging from $26.7^{\circ} \mathrm{C}$ to $35.4^{\circ} \mathrm{C}$ (Figure 3). In contrast to the $8.8^{\circ} \mathrm{C}$ range in initial skin temperature, the final skin temperature range of $5.8^{\circ} \mathrm{C}$ after Rest $3\left(31.5^{\circ} \mathrm{C}\right.$ to $\left.37.3^{\circ} \mathrm{C}\right)$ was more consistent across subject and thermistor location. Initial core temperatures across subjects were also more consistent, ranging from $37.3^{\circ} \mathrm{C}$ to $38.2^{\circ} \mathrm{C}\left(0.9^{\circ} \mathrm{C}\right.$ range). Example plots of thermistor and PTC results for two participants demonstrate the similarity in skin temperature increases, with one participant (No. 5) having similar temperatures across thermistor location and maintaining residual limb thermal comfort, while the other participant (No. 6) demonstrated a disparity in skin temperatures between TA and MG and perceived warming of his residual limb postexercise (Figure 5).

Core temperature ( $n=7$, one signal lost during collection) increased $0.9^{\circ} \mathrm{C}\left[0.7^{\circ} \mathrm{C}\right.$ to $\left.1.0^{\circ} \mathrm{C}\right]$ on average during Exercise $1(p<0.001)$ and remained elevated throughout the remainder of the testing session (Table 3), with the largest mean difference across consecutive sessions under $0.1^{\circ} \mathrm{C}$. Compared with Rest1, heart rate increased by an average of 50 beats per minute for both exercise bouts and 
JRRD, Volume 53, Number 5, 2016

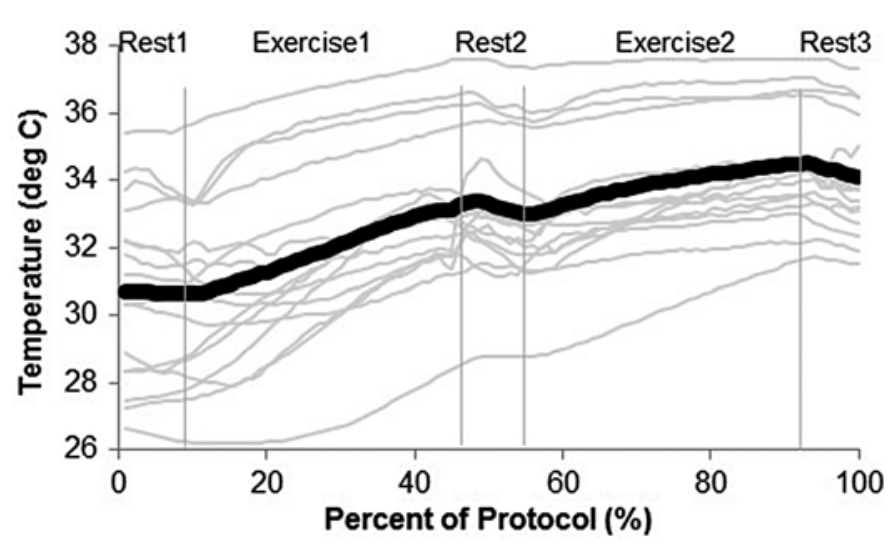

Figure 3.

Time normalized mean (thick black line) and individual (thin gray lines) residual limb skin temperature from four sites inside the prosthesis over a 75 min protocol, which began with an initial 5 min standing rest period (Rest1), followed by a snowshoe walk at self-selected speed (first 30 min exercise period [Exercise1]), a second 5 min standing rest period (Rest2), a second snowshoe walk at self-selected speed (second $30 \mathrm{~min}$ exercise period [Exercise2]), and a third 5 min standing rest period (Rest3).

remained elevated by approximately 20 beats per minute at the end of Rest2 and Rest3 (Table 3).

Participants walked at a mean cadence ( $n=5$, cadence was not documented for 3 participants) of $85 \pm 6$ steps per minute for a total of 5,100 \pm 380 steps during the two walking sessions. For the study duration, including walking to and from the van from the laboratory and the snowshoe site, participants took an average ( \pm 1SD) of $6,700 \pm$ 480 total steps.

\section{DISCUSSION}

Although increased heat and sweat at the skin-socket interface are common problems for individuals with lower-limb amputation, the effect of activity on residual limb skin temperature in more extreme ambient environments has incurred little study. We explored the effect of moderate activity in a cold environment on the residual limb skin temperature, core temperature, and PTC of participants with transtibial amputation. The results suggest that residual limb skin temperature and core temperature increased and remained elevated across relatively short rest periods; PTC also increased during activity but on average returned to initial comfort levels during the subsequent rest periods.

The present work adds to the body of literature that characterizes residual limb skin temperatures to provide a better understanding of the design criteria required for more comfortable prostheses. Prior work demonstrated that while standing for at least 15 min without a prosthesis at room temperature, the residual limb skin temperature of participants with amputation was on average $1^{\circ} \mathrm{C}$ cooler than the contralateral limb [7]. After donning a prosthesis and resting for $15 \mathrm{~min}$, residual limb skin temperatures increased by just under $1{ }^{\circ} \mathrm{C}$, with further increases after 10 min of slow walking at room temperature [1]. Klute et al. expanded on this research, reporting a similar temperature increase after donning a prosthesis, eventually reaching steady state after $25 \mathrm{~min}$ [2]. They reported a continuous increase in skin temperature up to $3.1^{\circ} \mathrm{C}\left[2.4^{\circ} \mathrm{C}\right.$ to $\left.3.8^{\circ} \mathrm{C}\right]$ after $30 \mathrm{~min}$ of walking at $0.7 \mathrm{~m} / \mathrm{s}$ at room temperature, which was similar to the present study's increase of $2.6^{\circ} \mathrm{C}\left[1.8^{\circ} \mathrm{C}\right.$ to $\left.3.5^{\circ} \mathrm{C}\right]$ despite ambient temperatures that were at least $20^{\circ} \mathrm{C}$ colder. Therefore, our results confirm that current prosthetic socket systems sufficiently insulate the residual limb during activity in a cold environment and a special thermal system is not required. In fact, since the residual limb skin temperature remained elevated during the rest periods, participants may benefit from a system capable of dissipating heat. The $5 \mathrm{~min}$ rest periods examined in this study were shorter than in a prior study to minimize

Table 3.

Mean \pm standard deviation residual limb skin temperature, core temperature, heart rate, and measured time across participants for each bout.

\begin{tabular}{lccccc}
\hline \multicolumn{1}{c}{ Variable } & Rest1 & Exercise1 & Rest2 & Exercise2 & Rest3 \\
\hline Residual Limb Temperature $\left({ }^{\circ} \mathrm{C}\right)$ & $30.6 \pm 2.6$ & $33.3 \pm 2.4$ & $33.0 \pm 2.3$ & $34.5 \pm 1.7$ & $34.1 \pm 1.8$ \\
Core Temperature $\left({ }^{\circ} \mathrm{C}\right)$ & $37.7 \pm 0.3$ & $38.5 \pm 0.6$ & $38.5 \pm 0.6$ & $38.6 \pm 0.4$ & $38.5 \pm 0.4$ \\
Heart Rate $(\mathrm{bpm})$ & $87 \pm 10$ & $139 \pm 16$ & $108 \pm 17$ & $137 \pm 15$ & $104 \pm 17$ \\
Measured Time $(\mathrm{min})$ & $6 \pm 2$ & $30 \pm 2$ & $8 \pm 3$ & $31 \pm 2$ & $5 \pm 1$ \\
\hline
\end{tabular}

Exercise1 = first 30 min exercise period, Exercise 2 = second 30 min exercise period, Rest $1=$ initial 5 min standing rest period, Rest $2=$ second 5 min standing rest period, Rest $3=$ third 5 min standing rest period. 


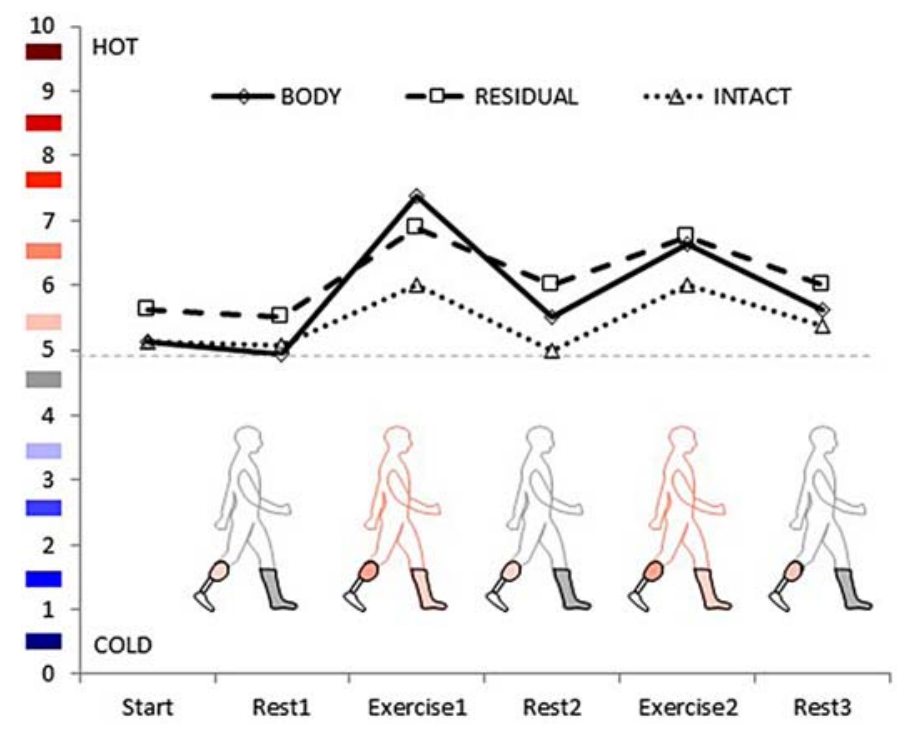

Figure 4.

Mean perceived thermal comfort (PTC) for three regions: residual limb, intact limb, and body at each transition on an 11-point Likert scale across participants, where 5 (gray) indicated the participant perceived a comfortable temperature, 10 (red) was perceived as the hottest temperature, and 0 (blue) was the coldest temperature. The color scale was used to map the PTC score at each region (lower drawings). The participants' reported scores were converted to the color code scheme to aid visual interpretation of the approximate changes in PTC for each region. Exercise1 = first $30 \mathrm{~min}$ exercise period, Exercise2 = second 30 min exercise period, Rest1 = initial 5 min standing rest period, Rest $2=$ second 5 min standing rest period, Rest $3=$ third 5 min standing rest period.

exposure to cold temperatures and likely explain the lack of significant decrease in temperature for Rest $2\left(-0.3^{\circ} \mathrm{C}\right)$ and Rest $3\left(-0.4^{\circ} \mathrm{C}\right)$ compared with the 60 min rest period in the prior study $\left(-0.9^{\circ} \mathrm{C}\right)$. An increased rate of cooling may have existed in the cold environment since 22 to 44 percent of the cooling occurred in just 8 percent of the time (5 versus $60 \mathrm{~min}$ ). However, further examination of longer rest periods in a cold environment is required to confirm whether a linear relationship is maintained.

Thermal comfort is a multifaceted measure that is influenced by activity level and the external environment and provides insight into the perception of changes in residual limb skin temperatures compared with the rest of the body. For example, sedentary subjects were previously reported to feel comfortable at a mean skin temperature of $33^{\circ} \mathrm{C}$ to $34^{\circ} \mathrm{C}$, while active participants preferred lower mean skin temperatures of $31^{\circ} \mathrm{C}$ [20]. Therefore, on average, the residual limb skin temperature of the participants with amputation at the start of Exercise1 $\left(30.6^{\circ} \mathrm{C}\right)$ was similar to previously reported active preferred skin temperature. This temperature was perceived as slightly warmer compared with the rest of the body and the intact limb and also varied by as much as $8^{\circ} \mathrm{C}$ across participants and thermistor location. Despite the skin temperature variation at initial rest, participants generally reported being comfortable in all regions, even those with higher residual limb skin temperatures (e.g., initial rest skin temperatures of $35.4^{\circ} \mathrm{C}$ and $26.2^{\circ} \mathrm{C}$ were both perceived as comfortable). Exercise caused an increase in skin temperature and the perception of warming across regions. In contrast, the short rests had little effect on skin temperature, but participants reported a return to thermal comfort, suggesting that either the small shift toward cooling or discontinued warming was sufficient for achieving comfort. This anticipatory response is similar to previous work that showed thermal sensors "leading" the body temperature changes [10].

The following limitations should be considered when interpreting the results of this study. One of the challenges associated with a field study that mimics real-life activities is the reduced control of confounding variables and missing data, which likely increases variability. Notably, the ambient temperature varied by approximately $5^{\circ} \mathrm{C}$, with varying amounts of precipitation (rain

Table 4.

Mean \pm standard deviation perceived thermal comfort (PTC) scores across participants for each bout and region.

\begin{tabular}{lccccc}
\hline \multicolumn{1}{c}{ PTC Score } & Rest1 & Exercise1 & Rest2 & Exercise2 & Rest3 \\
\hline Residual Limb & $5.5 \pm 1.1$ & $6.9 \pm 1.9$ & $6.0 \pm 1.1$ & $6.8 \pm 1.8$ & $6.0 \pm 1.1$ \\
Intact Limb & $5.1 \pm 1.1$ & $6.0 \pm 1.4$ & $5.0 \pm 0.8$ & $6.0 \pm 1.3$ & $5.4 \pm 0.9$ \\
Body & $4.9 \pm 1.4$ & $7.4 \pm 1.3$ & $5.5 \pm 1.3$ & $6.6 \pm 1.1$ & $5.6 \pm 0.9$ \\
\hline
\end{tabular}

Exercise1 = first 30 min exercise period, Exercise2 = second 30 min exercise period, Rest1 = initial 5 min standing rest period, Rest2 = second 5 min standing rest period, Rest 3 = third 5 min standing rest period. 


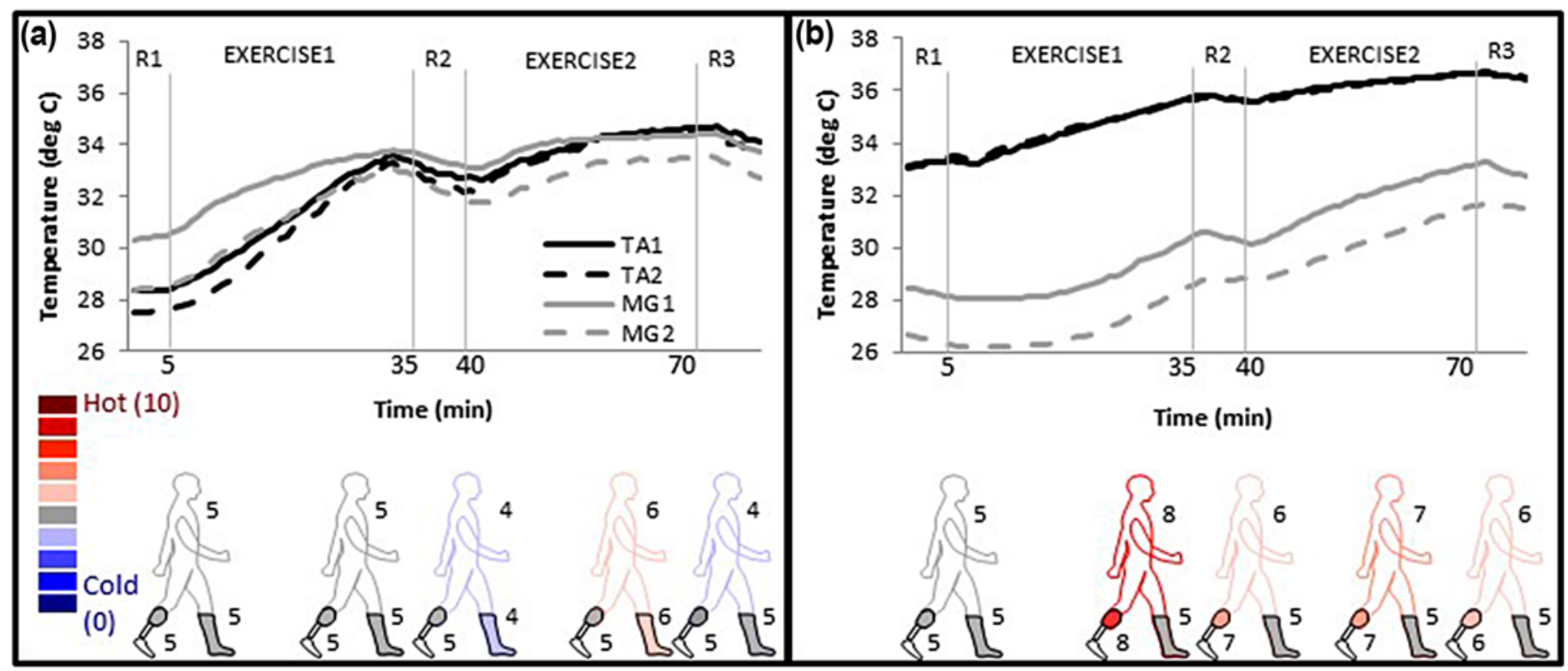

Figure 5.

Example thermistor plots separated by location (tibialis anterior: TA1, TA2 [proximal, distal] and medial gastrocnemius: MG1, MG2) and corresponding perceived thermal comfort (PTC) score by region (lower drawings with PTC score/color [0/blue-cold, 5/graycomfortable, 10/red-hot] for the body, residual, and intact limb) of two participants: (a) Participant 5 and (b) Participant 6 . All thermistor locations increased temperatures throughout the protocol with little cooling during rest; however, TA of participant 6 was more than $3^{\circ} \mathrm{C}$ higher in temperature throughout the protocol than MG. Notably, on the colder day $\left(-2^{\circ} \mathrm{C}\right.$ and snowing) participant 6 perceived the increase in residual limb skin temperature during exercise (8/red), and the temperature remained elevated during rest, while participant 5 reported that his residual limb remained comfortable (5/gray) throughout the protocol. Exercise $1=$ first 30 min exercise period, Exercise2 = second $30 \mathrm{~min}$ exercise period, R1 = initial 5 min standing rest period, R2 = second 5 min standing rest period, R3 = third 5 min standing rest period.

or snow), and participants were allowed to choose clothing that they deemed comfortable. To minimize the effects of confounding variables, we used a withinsubject study design and did not compare the effects of an intervention. Further testing in a controlled laboratory environment that strictly enforces the ambient temperature and clothing worn has merit, particularly for detecting changes due to an intervention that may be relatively small; however, the laboratory environment may impose unrealistic scenarios that are less clinically relevant, especially related to thermal perception. Alternatively, a field study provides the complete spectrum of conditions that contribute to altered temperature and perceived comfort [21], a powerful tool for understanding whether current prosthetic technology is sufficient in a real-world environment. The results presented in this study may also only apply to those with amputation from trauma. PTC and skin temperature may differ in diabetic patients because of peripheral nerve dysfunction and reduced blood flow, with supportive evidence that the most pronounced sensory deficit in the diabetic foot is elevated cold perception test scores [22]. Although no difference in residual limb temperature was found in a study of those with dysvascular $(n=10)$ versus traumatic $(n=21)$ amputation [7], additional study of skin temperature and PTC using larger samples of participants with diabetic versus traumatic amputation is warranted. Additionally, we intended to measure four distinct thermistor locations on the residual limb. Many sensors broke during the protocol (44\%; Table 1) because we chose a thin-gauge wire to minimize the risk of residual limb abrasion during an hour of moderate activity. A potential solution would be to validate an algorithm based on the correlation between liner-socket interface temperatures and skin-mounted thermistors [8] at a range of freezing ambient temperatures. Choosing to minimize risk at the expense of a more 
complete data set and the challenges associated with recruiting a narrow population of participants with lowerlimb amputation (i.e., subjects who participated in snow sports) limited our ability to compare limb temperatures by thermistor location. We have included example plots (Figure 5) to give the reader a sense of the variation by location; however, further research to identify whether overall differences exist by location is warranted.

\section{CONCLUSIONS}

Residual limb skin temperature, core temperature, and PTC increased during moderate activity in a cold environment. After a 5 min rest period, skin and core temperatures remained elevated while thermal comfort returned to pre-exercise levels, possibly in anticipation of cooling. Thermal comfort during activity in an outdoor, cold environment may be more easily attained than at room temperature if short rest periods are incorporated in the regimen.

\section{ACKNOWLEDGMENTS}

\author{
Author Contributions: \\ Study concept and design: G. K. Klute. \\ Acquisition of data: A. D. Segal. \\ Analysis and interpretation of data: A. D. Segal, G. K. Klute. \\ Drafting of manuscript: A. D. Segal, G. K. Klute. \\ Critical revision of manuscript for important intellectual content: \\ A. D. Segal, G. K. Klute. \\ Statistical analysis: A. D. Segal, G. K. Klute. \\ Obtained funding: G. K. Klute. \\ Study supervision: A. D. Segal, G. K. Klute.
}

Financial Disclosures: The authors have declared that no competing interests exist.

Funding/Support: This material was based on work supported by the Department of Veterans Affairs, Rehabilitation Research and Development Service (awards A2661C, A4843C, and A9243C).

Additional Contributions: We would like to thank Jane Shofer, MS, and Elizabeth Huff, BS, for their contributions to this manuscript.

Institutional Review: The institutional review board for this study was the Department of Veterans Affairs Puget Sound Health Care System IRB \#1.

Participant Follow-Up: The authors have no plans to notify the study subjects of the publication of this article because of a lack of contact information.

\section{REFERENCES}

1. Peery JT, Ledoux WR, Klute GK. Residual-limb skin temperature in transtibial sockets. J Rehabil Res Dev. 2005; 42(2):147-54. [PMID:15944879]

http://dx.doi.org/10.1682/JRRD.2004.01.0013

2. Klute GK, Huff E, Ledoux WR. Does activity affect residual limb skin temperatures? Clin Orthop Relat Res. 2014; 472(10):3062-67. [PMID:24964887] http://dx.doi.org/10.1007/s11999-014-3741-4

3. Ghoseiri K, Safari MR. Prevalence of heat and perspiration discomfort inside prostheses: Literature review. J Rehabil Res Dev. 2014;51(6):855-68. [PMID:25356571] http://dx.doi.org/10.1682/JRRD.2013.06.0133

4. Hachisuka K, Matsushima Y, Ohmine S, Shitama H, Shinkoda K. Moisture permeability of the total surface bearing prosthetic socket with a silicone liner: Is it superior to the patella-tendon bearing prosthetic socket? J UOEH. 2001;23(3):225-32. [PMID:11570046]

5. Klute GK, Rowe GI, Mamishev AV, Ledoux WR. The thermal conductivity of prosthetic sockets and liners. Prosthet Orthot Int. 2007;31(3):292-99. [PMID:17979015] http://dx.doi.org/10.1080/03093640601042554

6. Hagberg K, Brånemark R. Consequences of non-vascular trans-femoral amputation: A survey of quality of life, prosthetic use and problems. Prosthet Orthot Int. 2001;25(3): 186-94. [PMID:11860092] http://dx.doi.org/10.1080/03093640108726601

7. Harden RN, Gagnon CM, Gallizzi M, Khan AS, Newman D. Residual limbs of amputees are significantly cooler than contralateral intact limbs. Pain Pract. 2008;8(5):342-47. [PMID:18513229] http://dx.doi.org/10.1111/j.1533-2500.2008.00216.x

8. Mathur N, Glesk I, Buis A. Skin temperature prediction in lower limb prostheses. IEEE J Biomed Health Inform. 2016;20(1):158-65. [PMID:25389248] http://dx.doi.org/10.1109/JBHI.2014.2368774

9. Huff EA, Ledoux WR, Berge JS, Klute GK. Measuring residual limb skin temperatures at the skin-prosthesis interface. J Prosthet Orthot. 2008;20:170-73. http://dx.doi.org/10.1097/JPO.0b013e3181875b17

10. Gagge AP, Stolwijk JA, Hardy JD. Comfort and thermal sensations and associated physiological responses at various ambient temperatures. Environ Res. 1967;1(1):1-20. [PMID:5614624] http://dx.doi.org/10.1016/0013-9351(67)90002-3

11. Fanger PO. Assessment of man's thermal comfort in practice. Br J Ind Med. 1973;30(4):313-24. [PMID:4584998]

12. Leung SO. A comparison of psychometric properties and normality in 4-, 5-, 6-, and 11-point Likert scales. J Soc Serv Res. 2011;37(4):412-21. http://dx.doi.org/10.1080/01488376.2011.580697 
13. Coleman KL, Smith DG, Boone DA, Joseph AW, del Aguila MA. Step activity monitor: Long-term, continuous recording of ambulatory function. J Rehabil Res Dev. 1999;36(1):8-18. [PMID:10659890]

14. Hartsell H, Fitzpatrick D, Brand R, Frantz R, Saltzman C. Accuracy of a custom-designed activity monitor: Implications for diabetic foot ulcer healing. J Rehabil Res Dev. 2002;39(3):395-400. [PMID:12173759]

15. McDonald CM, Widman L, Abresch RT, Walsh SA, Walsh DD. Utility of a step activity monitor for the measurement of daily ambulatory activity in children. Arch Phys Med Rehabil. 2005;86(4):793-801. [PMID:15827934] http://dx.doi.org/10.1016/j.apmr.2004.10.011

16. Hothorn T, Bretz F, Westfall P. Simultaneous inference in general parametric models. Biom J. 2008;50(3):346-63. [PMID:18481363] http://dx.doi.org/10.1002/bimj.200810425

17. R Core Team. R: A language and environment for statistical computing. Vienna, Austria: R Foundation for Statistical Computing; 2014.

18. Bates D, Maechler M, Bolker B, Walker S. Lme4: linear mixed-effects models using Eigen and S4 [Internet]; 2014 April 4. Available from: https://cran.r-project.org/web/packages/lme4/index.html

19. Hothorn T, Bretz F, Westfall P. Simultaneous inference in general parametric models. Biom J. 2008;50(3):346-63. [PMID:18481363] http://dx.doi.org/10.1002/bimj.200810425
20. Fanger PO. Calculation of thermal comfort: Introduction of a basic comfort equation. Copenhagen: Danish Technical Press; 1967.

21. Karlsson IC, Rosenblad EF. Evaluating functional clothing in climatic chamber tests versus field tests: A comparison of quantitative and qualitative methods in product development. Ergonomics. 1998;41(10):1399-1420. [PMID:9802249] http://dx.doi.org/10.1080/001401398186171

22. Hyllienmark L, Jonsson B, Ekberg K, Lindström P. Abnormal cold perception in the lower limbs: A sensitive indicator for detection of polyneuropathy in patients with type 1 diabetes mellitus. Diabetes Res Clin Pract. 2009;85(3): 298-303. [PMID:19604594] http://dx.doi.org/10.1016/j.diabres.2009.06.009

Submitted for publication March 30, 2015. Accepted in revised form October 2, 2015.

This article and any supplementary material should be cited as follows:

Segal AD, Klute GK. Residual limb skin temperature and thermal comfort in people with amputation during activity in a cold environment. J Rehabil Res Dev. 2016; 53(5):619-28.

http://dx.doi.org/10.1682/JRRD.2015.03.0053

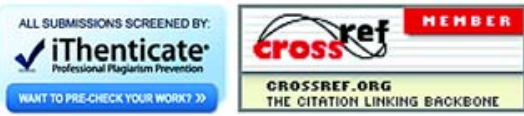

